\title{
KAJIAN KELEMBAGAAN DAN KEMITRAAN PEMASARAN KAYU KARET DI PROVINSI SUMATERA SELATAN
}

\author{
A study on Institutions and Partnership in Rubberwood Marketing \\ in South Sumatera Province
}

\author{
Dwi Shinta AGUSTINA, Lina Fatayati SYARIFA, dan Cicilia NANCY \\ Balai Penelitian Sembawa, Pusat Penelitian Karet \\ Jalan Raya Palembang - P. Balai KM 29, PO BOX 1127 Palembang 30001 \\ Email : dwishinta_sbw@yahoo.com
}

Diterima tanggal 6 Desember 2012 / Disetujui tanggal 8 Maret 2013

\begin{abstract}
In South Sumatra Province, several partnerhsip patterns between smallholders and rubber wood processing factories has been developed. This study aimed to analyze the institutional marketing of rubberwood, its constraints and efforts to optimize rubber wood processing factories. This study was conducted by survey method. The results showed that the source of rubber wood for industry was mostly derived from smallholders (74\%) and the rest (26\%) from big estates. As many as 68\% of smallholders who had replanted their rubber plants sold the rubber wood to the processing factories either through suppliers (73\%) or directly to the factories (27\%). The partnership patterns that had been conducted by factories were to give capital support to rubber nursery operators to help smallholders who needed rubber planting materials and to help smallhoders directly with rubber planting materials by calculating the price of rubber wood after wards. Road access from field to the factories and administrative systems for selling rubber wood had been constraints on rubber wood marketing. Licences to sell wood from cultivated plants should be simplified. The infrastructure (roads) from the rubber planting area to the rubber processing factories should be improved in order to keep the sustainability of rubber wood industry.
\end{abstract}

Keywords : Hevea brasiliensis, rubberwood, institution, marketing, partnership

\begin{abstract}
Abstrak
Di Provinsi Sumatera Selatan berkembang beberapa pola kemitraan antara petani dengan pabrik pengolahan kayu karet. Penelitian ini bertujuan melihat pola kelembagaan pemasaran kayu karet di Provinsi Sumatera Selatan, kendala dan upaya untuk mengoptimalkan pemanfaatan kayu karet serta kemitraan yang terjadi antara pabrik kayu karet dengan petani. Penelitian ini menggunakan metode survei. Hasil penelitian menunjukkan bahwa sumber kayu karet untuk industri saat ini sebagian besar $(74 \%)$ berasal dari perkebunan rakyat dan $26 \%$ dari perkebunan besar. Sebanyak $68 \%$ petani yang meremajakan kebun karetnya sudah menjual kayu karet ke industri pengolahan kayu baik melalui supplier $(73 \%)$ maupun menjual langsung ke pabrik (27\%). Pola kemitraan yang sudah dilaksanakan oleh pabrik di antaranya memberikan bantuan modal kepada penangkar untuk diberikan kepada petani yang membutuhkan bibit karet, dan membantu petani yang membutuhkan bibit karet dengan memperhitungkan harga kayu. Akses jalan kebun serta sistem kelengkapan administrasi bagi penjualan kayu karet masih menjadi kendala dalam pemasaran kayu karet. Perlu penyederhanaan perizinan untuk pemasaran kayu yang berasal dari tanaman budidaya seperti karet serta perbaikan sarana jalan menuju kebun untuk menjaga keberlangsungan industri kayu karet.
\end{abstract}

Kata kunci: Hevea brasiliensis, kayu karet, kelembagaan, pemasaran, kemitraan 


\section{PENDAHULUAN}

Kebutuhan bahan baku kayu nasional dari tahun ke tahun semakin meningkat. Pada tahun 2003, kebutuhan kayu sebesar 63 juta $\mathrm{m}^{3}$, sementara dalam rangka pelaksanaan kebijakan soft landing, pemerintah melalui Departemen Kehutanan pada tahun yang sama hanya memberikan jatah tebangan sebesar 6,8 juta $\mathrm{m}^{3}$. Data tersebut memperlihatkan adanya kesenjangan yang sangat besar antara produksi (supply) dengan kebutuhan (demand) bahan baku kayu yaitu sekitar 56 juta $\mathrm{m}^{3}$. Hal ini disebabkan menurunnya produktivitas hutan alam akibat tingkat laju kerusakan hutan yang sangat tinggi. Oleh karena itu perlu dicari alternatif pengganti kayu hutan alam yang memungkinkan untuk diekspor (Manurung, 2003).

Sebagai tanaman perkebunan, nilai ekonomi karet terletak pada kemampuannya menghasilkan lateks, sedangkan produk non-lateks seperti kayu karet pada awalnya dianggap sebagai hasil samping terutama sebagai sumber kayu bakar. Dengan berkembangnya teknologi pengolahan dan pengawetan kayu karet akhir-akhir ini dan terbatasnya ketersediaan kayu dari hutan untuk memenuhi pasokan kayu baik untuk pasar dalam negeri maupun luar negeri, menyebabkan permintaan terhadap kayu karet cukup tinggi dan setiap tahun terus meningkat. Tingginya permintaan terhadap kayu karet sejalan dengan membaiknya perekonomian dunia, meningkatnya jumlah penduduk, dan terbatasnya ketersediaan kayu hutan, terutama setelah kayu ramin, meranti putih, dan agathis dilarang untuk diekspor dalam bentuk kayu gergajian. (Boerhendhy et al., 2003).

Pemanfaatan kayu karet merupakan peluang baru untuk meningkatkan margin keuntungan dalam industri karet. Kayu karet banyak diminati oleh konsumen baik dari dalam maupun luar negeri, karena warnanya yang cerah dan coraknya seperti kayu ramin. Selain itu, kayu karet juga merupakan salah satu kayu tropis yang memenuhi persyaratan ecolabelling karena komoditas ini dibudidayakan (renewable) dengan kegunaan yang cukup luas, yaitu sebagai bahan baku perabotan rumah tangga, particle board, parquet, MDF (Medium Density Fibreboard) dan lain sebagainya.

Sumber kayu karet di Indonesia adalah perkebunan karet rakyat, perkebunan besar negara, dan perkebunan besar swasta. Kebun karet rakyat umumnya diremajakan atau dikonversi jika produksinya kurang dari $200 \mathrm{~kg}$ karet kering per ha per tahun, jumlah tanaman kurang dari 200 pohon per ha, umur tanaman lebih dari 30 tahun, kerusakan panel sadap karena penyadapan lebih dari $60 \%$, dan kondisi kebun sudah tidak ekonomis untuk dikelola (TKIHH Plus, 1987). Pola peremajaan yang umumnya diterapkan di perkebunan besar adalah 3\% dari total areal dengan siklus pertanaman 30 tahun. Dari peremajaan satu hektar kebun karet di perkebunan besar dapat diperoleh kayu karet sebanyak $75 \mathrm{~m}^{3}$ kayu gelondongan dengan potongan antara $1-1,5 \mathrm{~m}$ (Arsjad dan Dereinda, 1988). Volume kayu karet tersebut relatif rendah karena banyak tanaman yang bengkok atau tumbang karena angin dan batangnya benjol-benjol karena kesalahan penyadapan atau karena penyakit.

Volume kayu karet di perkebunan karet rakyat relatif rendah karena terdiri atas tanaman berbagai macam umur dan bercampur dengan tanaman lain, tanaman berasal dari biji, banyak batang yang bengkok dan benjol-benjol. Arsjad dan Dereinda (1988) memperkirakan volume kayu gelondongan dari kebun karet rakyat dan perkebunan berkisar $40-75 \mathrm{~m}^{3}$ per ha. Dengan asumsi perkebunan karet rakyat meremajakan 2\% dari total areal karet tua sedangkan perkebunan besar Negara dan swasta meremajakan 3\% dari total areal karet tua, maka potensi kayu karet yang diperoleh dari perkebunan rakyat dan perkebunan besar pada tahun 2010 adalah sebesar 577 ribu $\mathrm{m}^{3}$ per tahun.

Beberapa pola kemitraan antara pabrik kayu karet dengan petani karet rakyat telah dikembangkan di Sumatera Selatan. Berdasarkan hal tersebut, penelitian ini bertujuan untuk membahas tentang kelembagaan pemasaran kayu karet serta kemitraan yang terjadi antara pabrik kayu karet dan petani di Sumatera Selatan. 


\section{BAHAN DAN METODE}

Penelitian dilaksanakan dengan metode survei di beberapa kabupaten di Propinsi Sumatera Selatan yang memiliki industri pengolahan kayu karet, yaitu Kabupaten Ogan Ilir, Kabupaten Muara Enim, Kabupaten Musi Banyuasin, OKU Induk, dan Kabupaten Musi Rawas. Data yang dikumpulkan meliputi data primer dan data sekunder. Data primer diperoleh melalui wawancara dengan pabrik pengolah kayu karet, supplier, dan petani sedangkan data sekunder diperoleh dari data statistik, laporan, dan jurnal. Produk olahan yang diamati meliputi veneer, kayu pertukangan (sawn timber), MDF, dan kayu bakar untuk pabrik bata. Pengambilan sampel dilakukan dengan metode snow-ball, dimulai dari pabrik pengolahan kayu kemudian supplier, dan terakhir di tingkat petani. Data yang diperoleh dianalisis secara deskriptif.

\section{HASIL DAN PEMBAHASAN}

\section{Potensi Kayu Karet di Provinsi Sumatera Selatan}

Pembatasan penggunaan kayu yang berasal dari hutan alam sebagai bahan baku industri, bukanlah hal yang mencemaskan bagi pelaku industri kehutanan. Hal ini justru harus dijadikan tantangan agar industri tetap bertahan dan tidak terjadi pengurangan bahkan pemutusan hubungan kerja terhadap karyawan. Berbagai upaya yang bisa ditempuh antara lain melalui efisiensi penggunaan mesin dan penggantian sumber bahan baku yang berasal dari kayu hutan tanaman, hutan rakyat ataupun perkebunan.

Sesuai Peraturan Pemerintah No. 34/ 2002, kapasitas izin industri primer hasil hutan tidak boleh melebihi daya dukung hutan secara lestari dan sumber bahan baku industri primer hasil hutan selain dari hutan alam, dapat pula berasal dari hutan tanaman, hutan hak dan hasil dari perkebunan berupa kayu.

Guna mendukung program pelestarian hutan dengan cara tidak menggunakan kayu yang berasal dari hutan alam sebagai bahan baku industri kayu, pemerintah Provinsi Sumatera Selatan telah melakukan revitalisasi industri kehutanan. Program revitalisasi industri kehutanan yang dilakukan di Provinsi Sumatera Selatan berupa: perbaikan perizinan industri primer hasil hutan kayu (IPHHK) dari bahan baku kayu bulat yang berasal dari hutan alam menjadi bahan baku kayu yang berasal dari hutan tanaman ataupun hutan rakyat; mempermudah proses dan prosedur perizinan untuk industri yang menggunakan bahan baku kayu yang berasal dari hutan tanaman; pengetatan pemberian izin usaha (Antoro, 2012).

Provinsi Sumatera Selatan memiliki potensi usaha kayu karet mengingat luas lahan karet pada tahun 2009 mencapai 1,06 juta hektar, dan sebanyak 94,3\% merupakan karet rakyat (Disbun Sumsel, 2012). Dari total luasan karet, sebanyak 14\% (148 ribu hektar) merupakan areal karet tua yang siap diremajakan dan merupakan potensi bahan baku bagi industri pengolahan kayu karet, selebihnya tanaman menghasilkan (TM) seluas 655 ribu ha (62\%) dan tanaman belum menghasilkan (TBM) seluas 255 ribu ha (24\%) (Tabel 1).

Dilihat dari data pada Tabel 1, kabupaten-kabupaten potensial bahan baku kayu karet tua hasil peremajaan diantaranya adalah Kabupaten Musi Rawas, Muara Enim, Musi Banyuasin, dan OKI. Saat ini, di Kabupaten Musi Rawas, Muara Enim, dan Musi Banyuasin telah berdiri unit-unit pabrik sebagai perwakilan beberapa pabrik pengolahan kayu karet. Sementara di Kabupaten OKI, belum terdapat unit pabrik maupun pabrik pengolahan kayu karet. Hal ini dapat menjadi bahan pertimbangan bagi pihak pabrik atau pemerintah daerah untuk mendirikan unit pabrik di Kabupaten OKI mengingat potensi kayu karet tua hasil peremajaan kebun karet tua masih cukup besar.

Minat masyarakat menanam karet sangat tinggi, hal ini tercermin dari demikian luasnya penanaman karet yang dilakukan masyarakat. Sebagian besar kebun karet rakyat yang saat ini diremajakan (95\%) adalah kebun karet tradisional yang umumnya berupa hutan karet, sehingga selain tanaman karet dijumpai tanaman hutan lainnya. Hasil wawancara dengan beberapa supplier (pembeli kayu karet) menunjukkan bahwa pada saat kebun karet 
Tabel 1. Luas areal karet di Provinsi Sumatera Selatan berdasarkan Kabupaten, 2009 Table 1. Area of rubber in South Sumatra Province by District, 2009

\begin{tabular}{lccrc}
\hline \multicolumn{1}{c}{$\begin{array}{c}\text { Kabupaten } \\
\text { District }\end{array}$} & $\begin{array}{c}\text { TBM } \\
\text { Immature } \\
\text { rubber plant }\end{array}$ & $\begin{array}{c}\text { TM } \\
\text { Mature } \\
\text { rubber plant }\end{array}$ & $\begin{array}{c}\text { TT } \\
\text { Old rubber } \\
\text { plant }\end{array}$ & $\begin{array}{c}\text { Total } \\
\text { Total }\end{array}$ \\
\hline Lahat & 10.476 & 13.477 & 3.180 & 27.133 \\
Empat Lawang & 1.443 & 2.285 & 271 & 3.999 \\
Pagar Alam & 1.067 & 227 & 0 & 1.294 \\
Musi Banyuasin & 22.583 & 111.149 & 20.364 & 154.096 \\
Banyuasin & 20.499 & 53.680 & 8.696 & 82.875 \\
Musi Rawas & 36.979 & 155.595 & 55.611 & 248.185 \\
Lubuk Linggau & 2.160 & 8.223 & 3.356 & 13.739 \\
OKU & 18.577 & 41.416 & 8.616 & 68.609 \\
OKU Timur & 30.565 & 28.857 & 7.406 & 66.828 \\
OKU Selatan & 3.236 & 531 & 35 & 3.802 \\
OKI & 25.608 & 93.756 & 16.630 & 135.994 \\
Ogan Ilir & 7.956 & 18.032 & 1.263 & 27.251 \\
Muara Enim & 68.687 & 116.384 & 21.168 & 206.239 \\
Prabumulih & 5.559 & 11.244 & 1.573 & 18.376 \\
\hline Total & 255.395 & 654.856 & 148.169 & 1.058 .420 \\
\hline Sumber (source): Dinas Perkebunan Propinsi Sumatera Selatan (2012) & & \\
TBM = Tanaman belum menghasilkan (immature rubber plant) & & \\
TM = Tanaman menghasilkan (mature rubberplant & & \\
TT = Tanaman tua (old rubber plant) & & &
\end{tabular}

tradisional diremajakan, potensi kayu karet sekitar 58\% dari volume kayu, sedangkan $42 \%$ sisanya adalah kayu jenis lain yang juga memiliki nilai ekonomi seperti pelawan, pelangas, leban, seru dan racuk. Sementara pada perkebunan karet rakyat ex-proyek atau yang sudah teratur seluruhnya adalah tanaman karet.

Hasil estimasi luas areal penanaman karet di Sumatera Selatan yang dilakukan oleh Nancy, et al. (2011) disajikan pada Tabel 2. Luas areal penanaman karet seluas 46 ribu ha, sebesar $62 \%$ atau 28.650 ha merupakan peremajaan dan selebihnya $(38 \%)$ adalah perluasan. Areal perluasan umumnya terdapat di wilayah-wilayah yang selama ini bukan merupakan daerah konvensional karet, seperti Kabupaten Lahat, OKU Timur, dan OKI.

Estimasi peremajaan pada Tabel 2 menggunakan skenario pesimis bahwa setiap tahun hanya terdapat 30 petani per desa yang meremajakan karetnya masingmasing seluas 1 ha. Apabila diasumsikan areal peremajaan hanya 30 ha/desa dan dari setiap ha kebun karet tua dihasilkan kayu karet sebanyak 60 ton atau $40 \mathrm{~m}^{3}$, maka dari luas peremajaan seluas 28.650 ha akan diperoleh potensi kayu karet setiap tahun mencapai 1,7 juta $^{3}$ atau 1,1 juta ton.

Dari hasil studi diketahui bahwa terdapat delapan industri pengolahan kayu karet di Sumatera Selatan, yang tersebar di delapan kabupaten (Tabel 3). Hal ini merupakan bagian dari strategi investor untuk menghindari kendala persaingan bahan baku. Sumber utama bahan baku kayu karet saat ini berasal dari perkebunan rakyat (74\%) dan sebanyak $26 \%$ berasal dari perkebunan besar.

Data pada Tabel 3 menunjukkan bahwa produksi riil yang dicapai saat ini belum memenuhi kapasitas terpasang. Produksi riil rata-rata yang dicapai oleh 
Tabel 2. Estimasi luas pengembangan karet swadaya di Provinsi Sumatera Selatan per tahun

Table 2. Yearly estimate area of self-help rubber development in South Sumatra Province

\begin{tabular}{|c|c|c|c|c|c|c|c|}
\hline \multirow{2}{*}{$\begin{array}{c}\text { Kabupaten } \\
\text { / Kota } \\
\text { District } \\
\text { /City }\end{array}$} & \multirow{2}{*}{$\begin{array}{l}\text { Jumlah } \\
\text { desa } \\
\text { Number } \\
\text { of villages }\end{array}$} & \multirow{2}{*}{$\begin{array}{c}\% \text { Desa }^{2} \\
\text { karet }^{a} \\
\% \text { of } \\
\text { rubber } \\
\text { village }^{a}\end{array}$} & \multirow{2}{*}{$\begin{array}{l}\text { Jumlah } \\
\text { desa } \\
\text { penghasil } \\
\text { Karet } \\
\text { Number of } \\
\text { rubber } \\
\text { producing } \\
\text { villages }\end{array}$} & \multirow{2}{*}{$\begin{array}{c}\text { Total Area } \\
\text { (30 ha/desa) } \\
\text { Total of Area } \\
\text { (30 ha/village) }\end{array}$} & \multirow{2}{*}{$\begin{array}{l}\text { Indeks } \\
\text { peremajaan } \\
\text { Replanting } \\
\text { Index }\end{array}$} & \multicolumn{2}{|c|}{$\begin{array}{l}\text { Areal Swadaya (ha) } \\
\text { Self-help area (ha) }\end{array}$} \\
\hline & & & & & & $\begin{array}{l}\text { Peremajaan } \\
\text { Replanting }\end{array}$ & $\begin{array}{l}\text { Perluasan } \\
\text { Extension }\end{array}$ \\
\hline Banyuasin & 251 & 60 & 151 & 4.530 & 0,7 & 3.171 & 1.359 \\
\hline Lubuk Linggau & 30 & 10 & 3 & 90 & 1 & 90 & \\
\hline Pagar Alam & 25 & 10 & 3 & 90 & 0 & 0 & 90 \\
\hline Prabumulih & 13 & 90 & 12 & 360 & 1 & 360 & 0 \\
\hline Lahat & 508 & 40 & 203 & 6.090 & 0,5 & 3.045 & 3.045 \\
\hline Muara Enim & 279 & 80 & 223 & 6.690 & 0,9 & 6.021 & 669 \\
\hline MUBA & 200 & 80 & 160 & 4.800 & 0,9 & 4.320 & 480 \\
\hline Musi Rawas & 261 & 80 & 209 & 6.270 & 0,6 & 3.762 & 2.508 \\
\hline Ogan Ilir & 155 & 40 & 62 & 1.860 & 0,3 & 558 & 1.302 \\
\hline OKI & 374 & 60 & 224 & 6.720 & 0,5 & 3.360 & 3.360 \\
\hline OKU & 141 & 80 & 113 & 3.390 & 0,9 & 3.051 & 339 \\
\hline OKU Selatan & 200 & 10 & 20 & 600 & 0 & 0 & 600 \\
\hline OKU Timur & 253 & 60 & 152 & 4.560 & 0,2 & 912 & 3.648 \\
\hline Total & 2.596 & & 1.383 & 27.668 & & 28.650 & 17.400 \\
\hline
\end{tabular}

- ${ }^{a}$ Persentase desa karet merupakan nilai asumsi berdasarkan pengalaman di lapangan

${ }^{a}$ Percentage of rubber village in assumption value based on field experience

- ${ }^{\mathrm{b}}$ Indeks peremajaan merupakan nilai asumsi berdasarkan pengalaman lapang

${ }^{b}$ Replanting index is the assumption value based on field experience

Sumber (source): Nancy et al. (2011)

Tabel 3. Pabrik pengolahan kayu karet di Provinsi Sumatera Selatan Table 3. Rubberwood processing factory in South Sumatra Province

\begin{tabular}{|c|c|c|c|c|c|c|c|c|}
\hline \multirow[b]{2}{*}{$\begin{array}{l}\text { Pabrik } \\
\text { Factory }\end{array}$} & \multirow[b]{2}{*}{$\begin{array}{c}\text { Kabupaten } \\
\text { District }\end{array}$} & \multirow[b]{2}{*}{$\begin{array}{l}\text { Produk } \\
\text { Product }\end{array}$} & \multirow[b]{2}{*}{$\begin{array}{c}\text { Satuan } \\
\text { Unit }\end{array}$} & \multirow{2}{*}{$\begin{array}{l}\text { Kapasitas } \\
\text { pabrik } \\
\text { Factory } \\
\text { capacity }\end{array}$} & \multicolumn{2}{|c|}{$\begin{array}{l}\text { Produksi riil } \\
\text { Actual production }\end{array}$} & \multicolumn{2}{|c|}{$\begin{array}{l}\text { Sumber bahan baku } \\
\text { Source of raw material }\end{array}$} \\
\hline & & & & & $\mathrm{m}^{3}$ & $\%$ & $\begin{array}{l}\text { Perkebunan } \\
\text { besar (\%) } \\
\text { Estate (\%) }\end{array}$ & $\begin{array}{c}\text { Perkebunan } \\
\text { rakyat (\%) } \\
\text { Smallholding } \\
(\%)\end{array}$ \\
\hline PT. A & Ogan Ilir & veneer & $\mathrm{m}^{3}$ & 50.000 & 20.000 & 40 & 50 & 50 \\
\hline PT. B & Musi Banyuasin & veneer & $\mathrm{m}^{3}$ & 40.000 & 25.000 & 63 & 50 & 50 \\
\hline PT. C & Musi Rawas & veneer & $\mathrm{m}^{3}$ & 45.000 & 23.040 & 51 & 0 & 100 \\
\hline CV. D & Muara Enim & veneer & $\mathrm{m}^{3}$ & 5.000 & 2.500 & 50 & 0 & 100 \\
\hline CV. E & Banyuasin & veneer & $\mathrm{m}^{3}$ & 6.000 & 4.500 & 75 & 20 & 80 \\
\hline PT. F & Ogan Ilir & $M D F$ & ton & 163.056 & 110.000 & 67 & 30 & 70 \\
\hline PT. G & Banyuasin & $M D F$ & ton & 100.000 & 48.000 & 48 & 60 & 40 \\
\hline PT. H & OKU Induk & $\begin{array}{l}\text { Sawn } \\
\text { timber }\end{array}$ & $\mathrm{m}^{3}$ & 6.000 & 4.500 & 75 & 0 & 100 \\
\hline & Rata-rata & & & & & 59 & 26 & 74 \\
\hline
\end{tabular}

Sumber (source) : Data primer (2011) 
pabrik pada saat ini baru mencapai 59\% dari total kapasitas terpasang. Berdasarkan hal tersebut diketahui bahwa sebagian besar pabrik masih kekurangan bahan baku untuk mencapai produksi sesuai dengan kapasitas terpasang. Hal ini menjadi peluang bagi petani karet yang akan meremajakan kebun karetnya untuk menjual kayu karet ke pabrik pengolahan kayu karet.

Untuk dapat diolah, kayu karet yang dibeli oleh pabrik memiliki kriteria khusus sesuai dengan produk yang dihasilkan. Produk hasil pengolahan kayu karet yang ada di Sumatera Selatan meliputi produk veneer, MDF, dan kayu gergajian. Veneer merupakan irisan kayu tipis, biasanya lebih tipis dari $3 \mathrm{~mm}$, yang biasanya terpaku pada panel inti (biasanya kayu, papan partikel atau medium-density fiberboard) untuk menghasilkan panel datar seperti pintu, atasan dan panel untuk lemari, lantai parket dan bagian dari furniture. Veneer diperoleh dengan mengupas batang pohon atau dengan mengiris blok empat persegi panjang besar kayu yang dikenal sebagai flitches. Kriteria kayu karet yang dapat dimanfaat- kan sebagai bahan veneer adalah kayu karet harus memiliki panjang $130-135 \mathrm{~cm}$, diameter batang $>15 \mathrm{~cm}$, batang lurus, segar dan tidak ada percabangan (Gambar 1). Persyaratan ini sama halnya untuk produk kayu gergajian kayu karet (Gambar 2). Kayu gergajian digunakan sebagai bahan struktural untuk konstruksi, atau pulp kayu untuk produk kertas.

Sementara itu, untuk produk MDF, kayu karet harus memiliki panjang $2-2,5 \mathrm{~m}$, diameter batang $>8 \mathrm{~cm}$ (Gambar 3). Medium density fibreboard (MDF) adalah produk kayu rekayasa yang dibentuk dengan memecah kayu keras atau kayu lunak yang tersisa menjadi serat kayu, biasanya dalam sebuah defibrator yang digabungkan dengan lilin dan pengikat resin, dan membentuk panel dengan menerapkan suhu tinggi dan tekanan. MDF lebih padat daripada kayu lapis, terdiri dari serat dipisahkan, tetapi dapat digunakan sebagai bahan bangunan seperti halnya kayu lapis.

Kondisi bahan baku kayu karet yang dapat digunakan untuk pabrik batu bata ditampilkan pada Gambar 4.

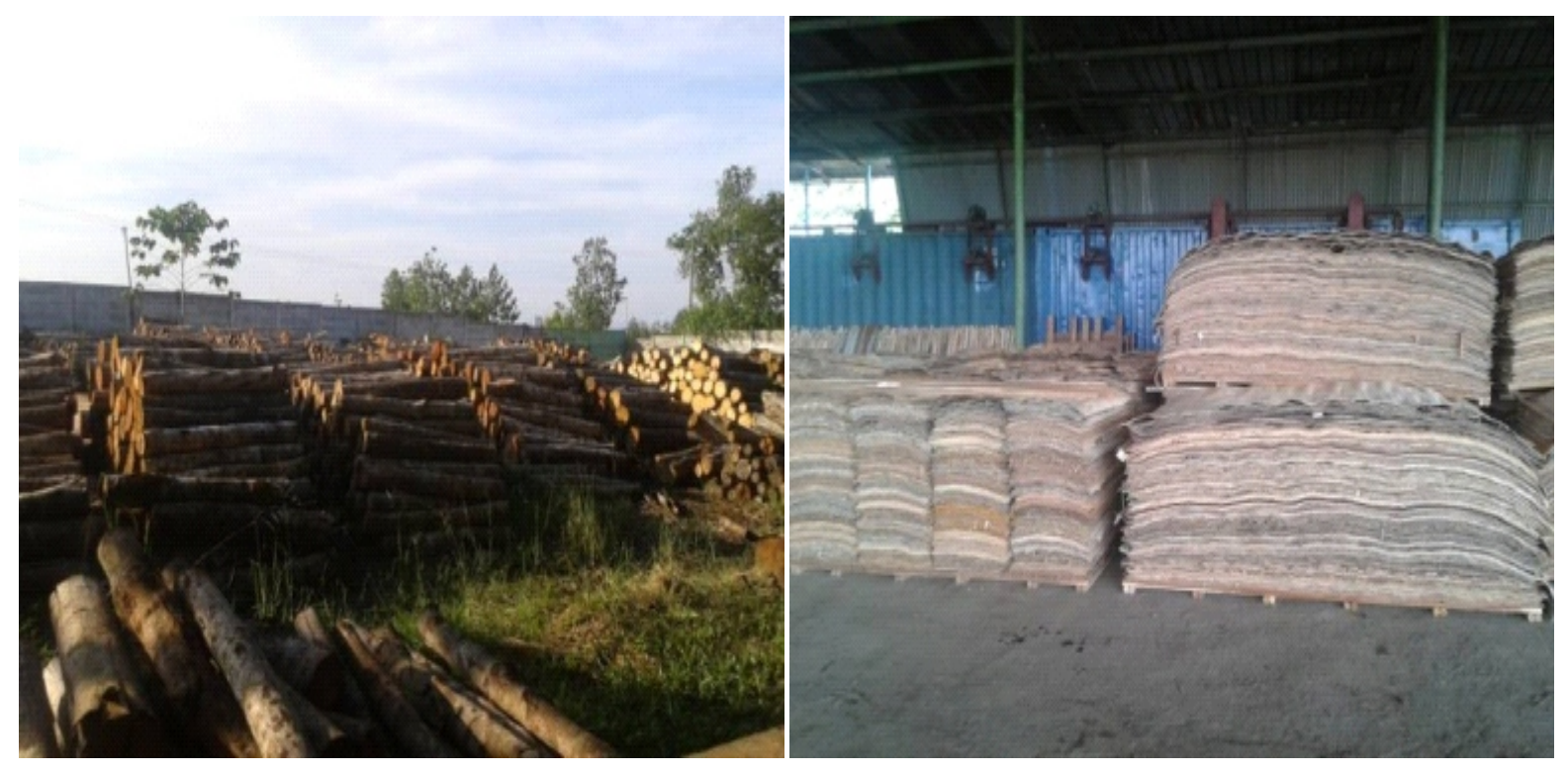

Gambar 1. Bahan baku dan produk veneer yang dihasilkan oleh salah satu pabrik pengolahan kayu karet di Sumatera Selatan

Figure 1. Raw material and veneer product produced by one of rubberwood processing factories in South Sumatra 

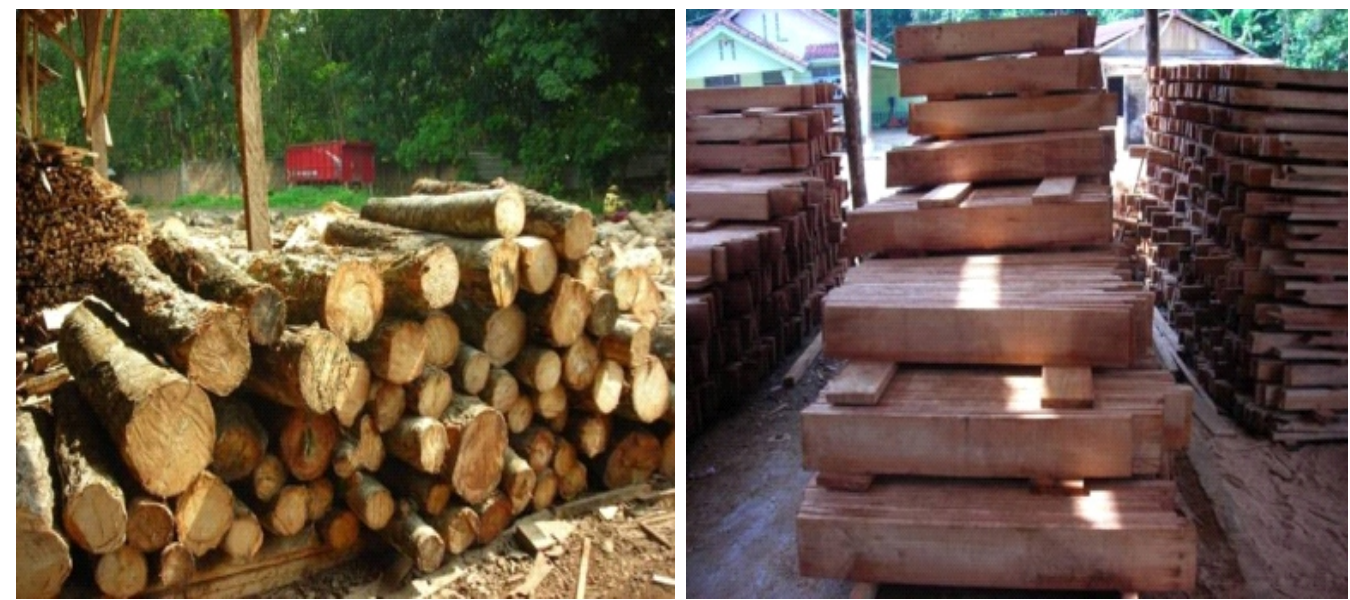

Gambar 2. Bahan baku dan produk kayu gergajian yang dihasilkan oleh salah satu pabrik pengolahan kayu karet di Sumatera Selatan

Figure 2. Raw material and product of sawn timber produced by one of rubberwood processing factories in South Sumatra
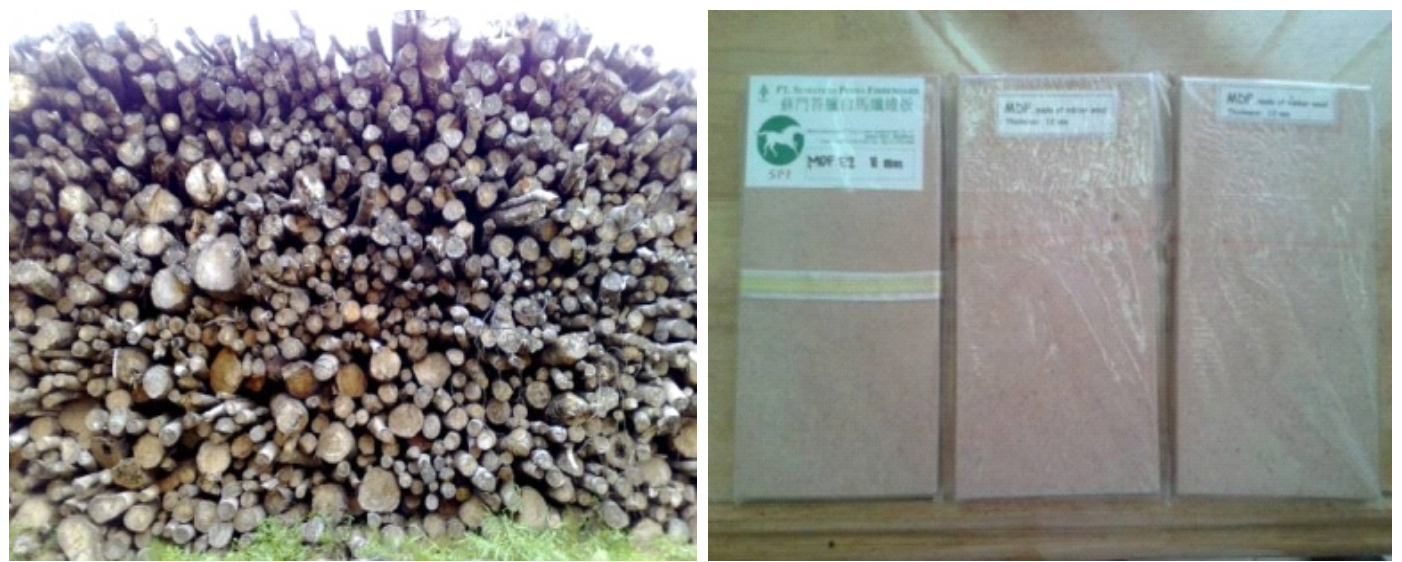

Gambar 3. Bahan baku dan produk MDF yang dihasilkan oleh salah satu pabrik pengolahan kayu karet di Sumatera Selatan

Figure 3. Raw material and MDF product produced by one of rubberwood processing factories in South Sumatra
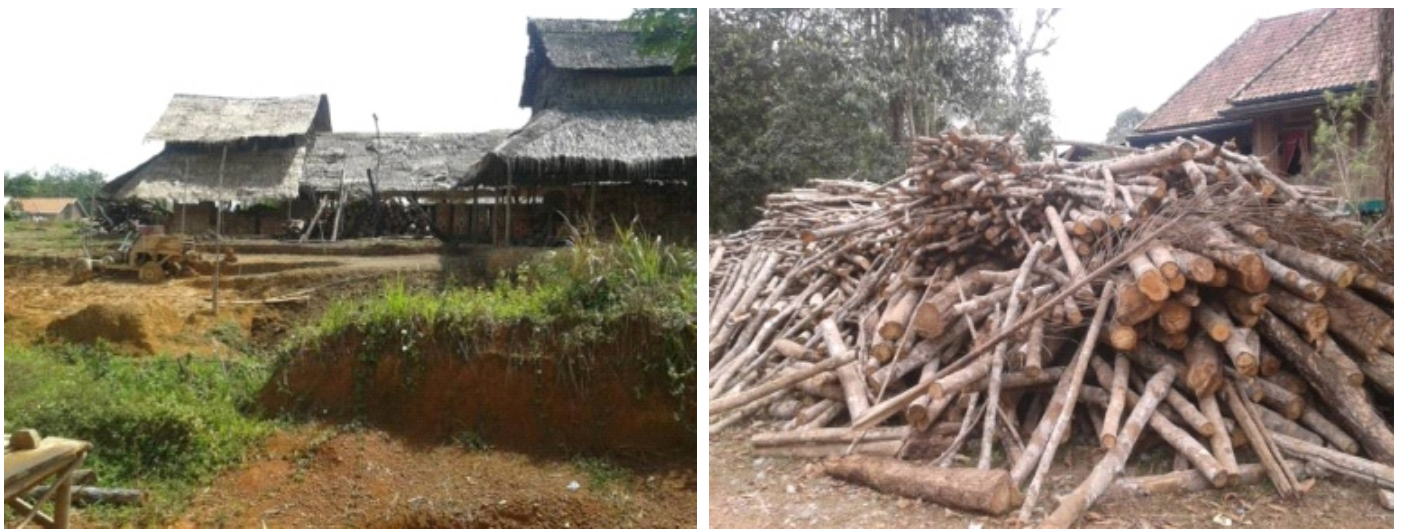

Gambar 4. Bahan baku kayu karet untuk pembuatan batu bata di Sumatera Selatan Figure 4. Raw material of rubberwood in brick production in South Sumatra 


\section{Pemasaran Kayu Karet}

Analisis kelembagaan pemasaran kayu karet dilakukan di beberapa kabupaten sentra karet di Sumatera Selatan. Dari hasil penelitian diketahui bahwa di daerahdaerah sentra karet telah berdiri industri pengolahan kayu karet. Secara umum, pola pemasaran kayu karet yang ditemui di lapangan ditampilkan pada Gambar 5 .

Dari Gambar 5 terlihat bahwa sebagian besar $(73 \%)$ bahan baku untuk industri pengolahan kayu karet diperoleh melalui supplier log yang membeli kayu karet dari petani yang meremajakan kebun karet tuanya. Dari $73 \%$ tersebut, sebanyak 42\% supplier menjual kepada unit pabrik, sedangkan sebanyak 31\% menjual langsung ke industri pengolahan kayu karet. Sementara itu, sebanyak $27 \%$ bahan baku diperoleh industri pengolahan kayu dengan membeli langsung dari petani.

Kerja sama antara pabrik dengan suplier umumnya tidak terikat kontrak, karena supply kayu karet sangat tergantung musim, sehingga apabila musim kemarau dikhawatirkan terjadi over supply, sebaliknya musim hujan stok bahan baku kosong. Rata-rata masing-masing pabrik memiliki 3-5 orang supplier yang aktif sebagai pemasok kayu karet. Menurut informasi yang diperoleh dari pihak pabrik, saat ini supply kayu karet lebih mudah didapat dibandingkan dengan kayu hutan lainnya.
Informasi adanya areal yang akan diremajakan biasanya berasal dari supplier, sementara proses pengurusan IPKTM (Izin Pemanfaatan Kayu pada Tanah Milik) sampai terbitnya SKAU (Surat Keterangan Asal Usul) di Dinas Kehutanan dan Kepala Desa umumnya diurus oleh pihak pabrik. Pada saat pengajuan IPKTM harus dilampirkan surat tanah, selanjutnya petugas meninjau lokasi kebun yang akan diremajakan. Pembayaran dari pabrik kepada supplier bervariasi, ada yang langsung dibayar setelah dilakukan pengukuran $(43 \%), 2$ hari setelah pengukuran (14\%), dan 1-3 minggu setelah pengukuran $(43 \%)$.

Harga kayu karet di tingkat pabrik bervariasi. Biaya operasional yang meliputi biaya tebang, biaya muat, biaya angkut, dan biaya bongkar ditanggung oleh supplier. Perincian harga, biaya yang dikeluarkan dan keuntungan supplier disajikan pada Tabel 4.

Data pada Tabel 4 menunjukkan bahwa kayu karet dapat memberikan keuntungan bagi pihak supplier. Keuntungan yang diperoleh supplier pada masing-masing industri pengolahan berbeda-beda karena harga jual kayu dan biaya yang dikeluarkan juga berbeda. Keuntungan terbesar diperoleh dari $M D F$ yaitu sebesar Rp 750 ribu - Rp 2,9 juta per truk. Hal ini disebabkan karena pada pengolahan $M D F$, semua bagian pohon karet dapat dimanfaatkan sehingga volume per

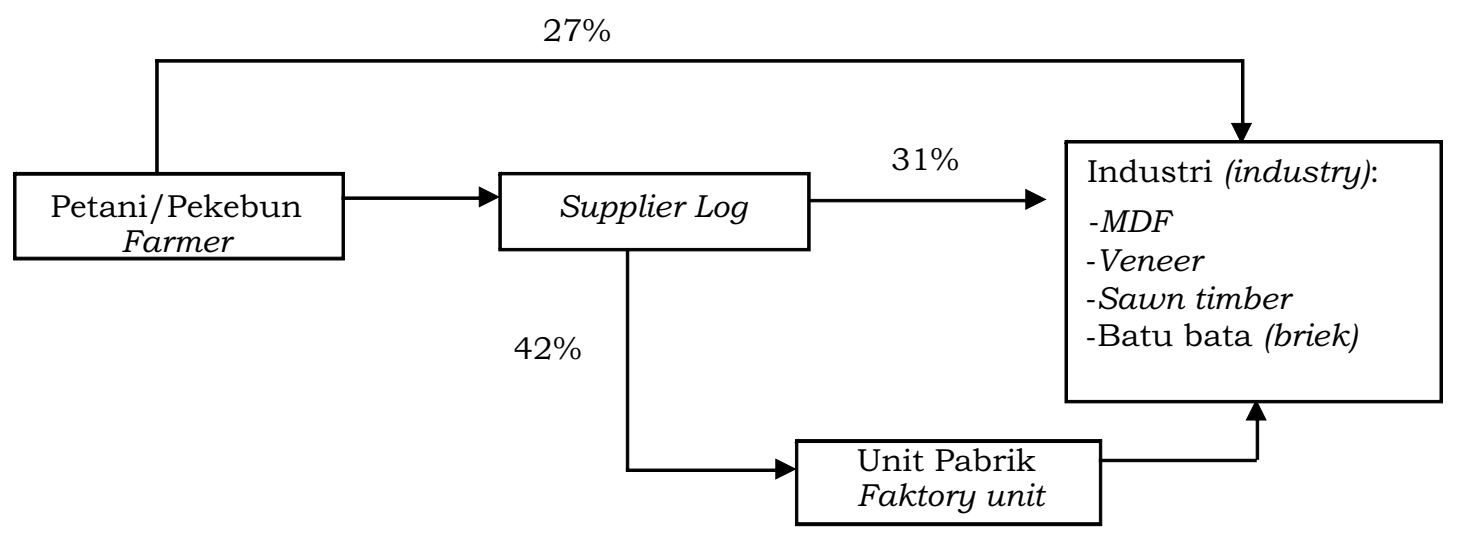

Gambar 5. Rantai pemasaran kayu karet, 2011

Figure 5. Rubberwood marketing chain, 2011 
Tabel 4. Analisis keuntungan supplier kayu karet, 2011

Table 4. Profitability analysis of rubberwood supplier, 2011

\begin{tabular}{|c|c|c|c|c|}
\hline \multirow[b]{2}{*}{$\begin{array}{c}\text { Uraian } \\
\text { Description }\end{array}$} & \multicolumn{4}{|c|}{$\begin{array}{l}\text { Produk } \\
\text { Product }\end{array}$} \\
\hline & $\begin{array}{c}\text { Veneer } \\
\text { (Rp/truk) } \\
\text { Rp/truck }\end{array}$ & $\begin{array}{c}\text { MDF } \\
\text { (Rp/truk) } \\
\text { Rp/truck }\end{array}$ & $\begin{array}{c}\text { Batu Bata } \\
\text { (Rp/truk) } \\
\text { (Brick) } \\
(\text { Rp/truck) }\end{array}$ & $\begin{array}{c}\text { Kayu gergajian } \\
\text { (Rp/truk ) } \\
\text { Sawn timber } \\
\text { (Rp/truck) }\end{array}$ \\
\hline $\begin{array}{l}\text { Harga kayu karet } \\
\text { Price of rubberwood } \\
\text { Biaya-biaya (Costs) }\end{array}$ & $\begin{array}{r}1.520 .000 \mathrm{~s} / \mathrm{d} \\
2.000 .000\end{array}$ & $\begin{array}{r}3.605 .800 \mathrm{~s} / \mathrm{d} \\
5.769 .200\end{array}$ & 400.000 & 1.923 .100 \\
\hline $\begin{array}{l}\text { - Biaya tebang } \\
\text { Cutting down cost }\end{array}$ & 200.000 & 504.750 & 0 & 230.800 \\
\hline $\begin{array}{l}\text { - Biaya muat } \\
\text { Loading cost }\end{array}$ & 300.000 & 721.150 & 0 & 230.800 \\
\hline $\begin{array}{l}\text { - Biaya angkutan } \\
\text { Transportation cost }\end{array}$ & 480.000 & 1.153 .850 & 60.000 & 538.500 \\
\hline $\begin{array}{l}\text { - Biaya bongkar } \\
\text { Unloading cost }\end{array}$ & 40.000 & 43.300 & 0 & 0 \\
\hline $\begin{array}{l}\text { - Biaya gesek } \\
\text { Sowing cost }\end{array}$ & 0 & 0 & 0 & 461.500 \\
\hline $\begin{array}{l}\text { - Biaya lainnya } \\
\text { Other cost }\end{array}$ & 50.000 & 432.700 & 10.000 & 0 \\
\hline $\begin{array}{l}\text { - Total Biaya } \\
\text { Total cost }\end{array}$ & 1.070 .000 & 2.855 .750 & 70.000 & 1.461 .600 \\
\hline $\begin{array}{l}\text { Keuntungan } \\
\text { Benefit }\end{array}$ & $\begin{array}{r}450.000 \mathrm{~s} / \mathrm{d} \\
930.000\end{array}$ & $\begin{array}{c}750.050 \mathrm{~s} / \mathrm{d} \\
2.913 .450\end{array}$ & 330.000 & 461.500 \\
\hline
\end{tabular}

Sumber (source): Data primer (primary data), 2011

truk dapat lebih banyak dibandingkan dengan veneer maupun sawn timber. Muatan kayu untuk bahan baku MDF per truk dapat mencapai $7 \mathrm{~m}^{3}$ sedangkan muatan kayu untuk bahan baku veneer dan sawn timber hanya berkisar antara 4-5 $\mathrm{m}^{3}$. Tingkat keuntungan terkecil pemanfaatan kayu karet diperoleh pada usaha batu bata yaitu Rp 330 ribu per truk. Biaya tebang dan muat supplier yang menjual kayu karet ke pabrik batu bata tidak ada karena kayu sudah di tebang oleh petani dan diletakkan di pinggir jalan kebun sehingga supplier tinggal mengangkut saja. Secara keseluruhan, pengolahan kayu karet menjadi beberapa produk olahan telah memberikan nilai tambah dibandingkan jika kayu karet hanya dimanfaatkan sebagai kayu bakar.
Selain di tingkat supplier, penjualan kayu karet juga memberikan keuntungan bagi pihak petani. Kayu karet yang semula hanya dibakar dan tidak dimanfaatkan, saat ini dapat memberikan pendapatan tambahan terutama untuk biaya peremajaan. Dari hasil studi diketahui bahwa di kabupaten-kabupaten sentra karet di Provinsi Sumatera Selatan, peremajaan per tahun per desa adalah berkisar 13 - 63 ha atau rata-rata 39 ha (Tabel 5). Dari hasil penjualan kayu karet ke pabrik pengolahan kayu karet, pendapatan yang diperoleh petani berkisar antara Rp 2 juta - Rp 14 juta/ ha dengan jumlah tegakan pada saat peremajaan adalah 300 - 500 batang per ha. Uang hasil penjualan kayu karet dimanfaatkan petani sebagai tambahan biaya untuk pembukaan kebun karet baru. 
Tabel5. Rata-rata peremajaan dan pemanfaatan kayu karet di kabupaten sentra karet Propinsi Sumatera Selatan, 2011

Table 5. Average replanting area and usage of rubberwood in the district of rubber producing centers of rubber in South Sumatra Province, 2011

\begin{tabular}{|c|c|c|c|c|c|c|}
\hline \multirow{2}{*}{$\begin{array}{c}\text { Kabupaten } \\
\text { District }\end{array}$} & \multirow{2}{*}{$\begin{array}{c}\text { Rata-rata } \\
\text { peremajaan } \\
\text { per desa (ha) } \\
\text { The average } \\
\text { of replanting } \\
\text { per village } \\
\text { (ha) }\end{array}$} & \multirow{2}{*}{$\begin{array}{l}\text { Ya } \\
(\%) \\
\text { Yes } \\
(\%)\end{array}$} & \multicolumn{2}{|c|}{$\begin{array}{l}\text { Penjualan kayu karet } \\
\text { Purchasing of rubber wood }\end{array}$} & \multirow{2}{*}{$\begin{array}{l}\text { Tidak } \\
(\%) \\
\text { No } \\
(\%)\end{array}$} & \multirow{2}{*}{$\begin{array}{l}\text { Keberadaan } \\
\text { supplier kayu } \\
\text { tingkat desa } \\
\text { (orang) } \\
\text { The existence of } \\
\text { rubberwood } \\
\text { supplier at } \\
\text { village level } \\
\text { (person) } \\
\end{array}$} \\
\hline & & & $\begin{array}{l}\text { Sistem penjualan } \\
\text { System of Purchasing }\end{array}$ & $\begin{array}{l}\text { Sistem Pembayaran } \\
\text { System of payment }\end{array}$ & & \\
\hline Banyuasin & 18 & 80 & $\begin{array}{l}\text { Melalui supplier, supplier } \\
\text { yang menebang } \\
\text { Through supplier, cutting } \\
\text { down of the trees was } \\
\text { conducted by supplier }\end{array}$ & $\begin{array}{l}\text { Cash; bayar separuh di } \\
\text { muka dilunasi pada akhir } \\
\text { penebangan } \\
\text { Cash, } 50 \% \text { down payment } \\
\text { and repaid at the end of the } \\
\text { logging }\end{array}$ & 20 & $8-10$ \\
\hline $\begin{array}{l}\text { Musi } \\
\text { Banyuasin }\end{array}$ & 57 & 70 & $\begin{array}{l}\text { Melalui supplier, supplier } \\
\text { yang menebang } \\
\text { Through supplier, cutting } \\
\text { down of the trees was } \\
\text { conducted by supplier }\end{array}$ & Cash & 30 & $1-3$ \\
\hline Musi Rawas & 54 & 70 & $\begin{array}{l}\text { melalui supplier petani yang } \\
\text { menebang; petani yg } \\
\text { mengantar langsung ke pabri } \\
\text { through supplier, cutting } \\
\text { down of the trees was } \\
\text { conducted by smallholders } \\
\text { and they transport to the } \\
\text { factory }\end{array}$ & $\begin{array}{l}\text { Cash; 3-7 hari setelah } \\
\text { diangkut } \\
\text { x Cash, the paymentafter } 3-7 \\
\text { days of transporting }\end{array}$ & 30 & 2 \\
\hline OKI & 13 & 0 & - & - & 100 & - \\
\hline Ogan Ilir & 63 & 100 & $\begin{array}{l}\text { Melalui supplier, supplier } \\
\text { yang menebang } \\
\text { Through supplier, cutting } \\
\text { down of the trees was } \\
\text { conducted by supplier }\end{array}$ & $\begin{array}{l}\text { Cash; bayar separuh di } \\
\text { muka dilunasi pada akhir } \\
\text { penebangan } \\
\text { Cash, } 50 \% \text { down payment } \\
\text { and repaid at the end of the } \\
\text { logging }\end{array}$ & 0 & 1 \\
\hline Muara Enim & 31 & 100 & $\begin{array}{l}\text { Melalui supplier, supplier } \\
\text { yang menebang } \\
\text { Through supplier, cutting } \\
\text { down of the trees was } \\
\text { conducted by supplier }\end{array}$ & $\begin{array}{l}\text { Cash; bayar separuh di } \\
\text { muka dilunasi pada akhir } \\
\text { penebangan } \\
\text { Cash, } 50 \% \text { down payment } \\
\text { and repaid at the end of the } \\
\text { logging }\end{array}$ & 0 & 3 \\
\hline OKU Induk & 53 & 20 & $\begin{array}{l}\text { Pihak pabrik langsung } \\
\text { membeli ke petani } \\
\text { Factory bought the trees } \\
\text { directly from smallholders }\end{array}$ & Cash & 80 & 1 \\
\hline Prabumulih & 25 & 100 & $\begin{array}{l}\text { Melalui supplier, supplier } \\
\text { yang menebang } \\
\text { Through supplier, cutting } \\
\text { down of the trees was } \\
\text { conducted by supplier }\end{array}$ & Cash & 0 & 1 \\
\hline $\begin{array}{l}\text { Rata-rata } \\
\text { (Average) }\end{array}$ & 39 & 68 & & & 32 & \\
\hline
\end{tabular}


Data pada Tabel 5 menunjukkan bahwa sekitar $68 \%$ petani yang meremajakan kebun karet tuanya sudah menjual kayu karet ke industri pengolahan kayu, seperti $M D F$, veneer, sawn timber, dan bangsal batu bata. Sebanyak 32\% petani tidak menjual kayu karet karena di daerah tersebut belum terdapat areal peremajaan (tanaman karet masih berupa tanaman muda dan tanaman menghasilkan) dan tidak ada supplier yang masuk ke desa karena kondisi kebun jauh dan sulit dijangkau oleh kendaraan. Pada umumnya, petani yang menjual kayu karet ke pabrik $M D F$, veneer, dan sawn timber memborongkan kayu karetnya kepada supplier, selanjutnya supplier melakukan penebangan kayu. Sementara itu, petani yang menjual kayu karet ke bangsal batu bata, menebang sendiri kayu karetnya dan meletakkannya di pinggir kebun/jalan sambil menunggu supplier yang datang membeli kayu karetnya. Sistem pembayaran pada umumnya adalah pembayaran secara langsung oleh supplier kepada petani setelah melakukan pengukuran kayu yang akan ditebang. Selain dengan sistem pembayaran secara cash, ada juga supplier yang melakukan pembayaran sebanyak dua kali (separuh di awal dan dilunasi pada akhir penebangan).
Dari hasil wawancara dengan pihak pabrik diketahui bahwa produk olahan kayu karet seperti $M D F$, veneer, dan sawn timber dipasarkan di dalam negeri (65\%) dan ke luar negeri (35\%). Wilayah pemasaran dalam negeri meliputi Jakarta, Jambi, Sumatera Selatan, Yogyakarta, Surabaya, Tangerang, dan Bandung, sedangkan pasar ekspor meliputi wilayah Asia seperti Malaysia, Thailand, Vietnam, India, RRC, dan wilayah Timur Tengah. Untuk produk MDF, jenis produk yang diproduksi tergantung permintaan konsumen berdasarkan Standar European MDF Board (EMB), Japan Industrial Standard (JIS); California Air Regulatory Board (CARB). Di antara standarstandar tersebut, Japan Industrial Standar merupakan standar yang paling tinggi karena biaya produksi lebih mahal.

\section{Kendala-Kendala yang Dihadapi oleh Industri Pengolahan Kayu Karet}

Dari hasil penelitian diketahui beberapa kendala usaha industri pengolahan kayu karet, di antaranya:

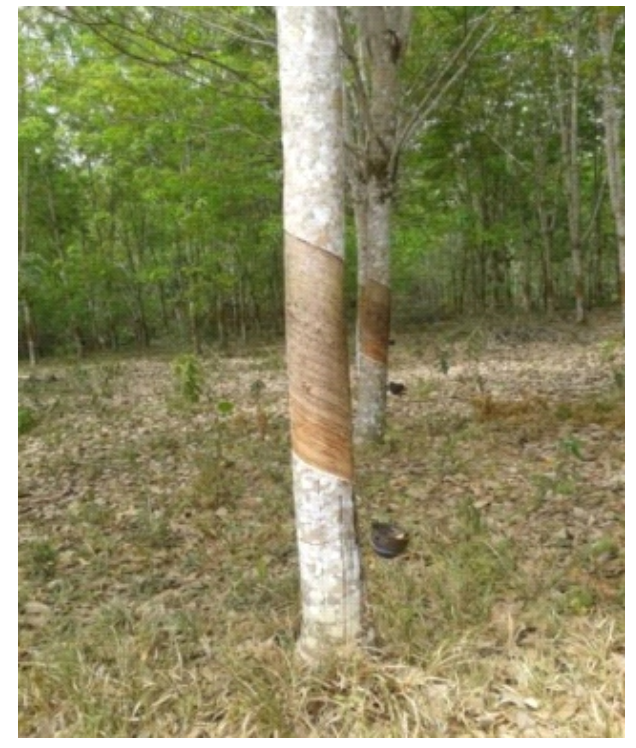

(a)

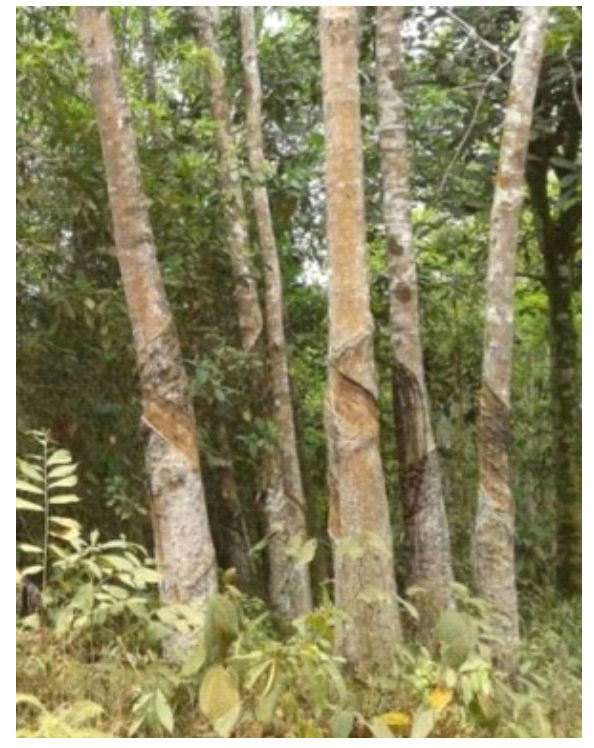

(b)

Gambar 6. Kondisi kayu karet pada penyadapan (a) benar; (b) berat yang melukai kambium

Figure 6. Rubberwood on tapping condition (a) right; (b) over tapping 


\section{Harga karet alam yang tinggi}

Pada saat harga karet meningkat, sebagian besar petani memutuskan menunda peremajaan karetnya. Sebagai contoh untuk kebun karet tua yang hanya menghasilkan $50 \mathrm{~kg}$ slab/minggu, petani masih menerima Rp 1 juta per minggu. Kondisi saat ini petani akan meremajakan kebun apabila hasil karet kurang dari $25 \mathrm{~kg}$ slab/ minggu. Berdasarkan hasil wawancara dengan petani diketahui bahwa saat ini dengan kondisi harga karet yang baik, petani baru akan meremajakan kebun karet jika produksi yang dicapai kurang 5 $\mathrm{kg} /$ hari.

\section{Keterbatasan jalan produksi di kebun}

Kebun karet rakyat sebagian besar terletak di pedalaman yang hanya dapat dilalui jalan setapak. Supplier adakalanya harus membuat jalan khusus untuk mengeluarkan kayu, yang tidak jarang harus meminta izin pada kebun yang bersebelahan. Masalah lain apabila harus melewati kebun produktif dan harus memberikan kompensasi yang nilainya tinggi. Hal ini akan menambah biaya bagi pihak supplier.

\section{Penyadapan tidak terkendali}

Penyadapan karet umumnya dilakukan tidak terkendali, petani melakukan over tapping yang mengakibatkan kulit tanaman rusak, dan konsumsi kulit boros, sehingga umur ekonomis tanaman menjadi singkat. Mutu bidang sadap yang rendah akan menyebabkan rendahnya rendemen produksi dan mutu produk yang dihasilkan. Kondisi bidang sadap yang ditemukan di perkebunan karet rakyat ditampilkan pada Gambar 6a dan 6b.

\section{Faktor musim/cuaca}

Pasokan kayu karet sangat dipengaruhi oleh musim pembukaan lahan, karena petani umumnya melakukan tebas tebang pada musim kemarau (JuniSeptember). Di samping itu supply kayu karet dipengaruhi faktor cuaca, pada musim hujan kondisi jalan di kebun umumnya rusak, sehingga kayu sulit untuk dikeluarkan dari kebun.

Dari hasil wawancara dengan pihak pabrik diketahui bahwa pada musim kemarau yaitu Juni - September pasokan kayu sangat tinggi, dan biasanya dijadikan stok bahan baku untuk musim hujan, saat supply kayu menurun drastis. Cadangan kayu karet untuk veneer dan MDF hanya dapat disimpan maksimal selama 3 bulan, sehingga pihak pabrik harus dapat menghitung ketersediaan kayu yang ada, agar pabrik dapat beroperasi secara berkesinambungan. Upaya yang dilakukan pihak pabrik antara lain mencampur antara stok kayu lama dan baru. Sementara ketahanan kayu karet untuk sawn timber hanya 3 hari.

Upaya yang dilakukan pabrik agar pabrik dapat tetap beroperasi pada saat supply dari perkebunan karet rakyat merosot, adalah memasok kayu dari perkebunan besar baik perkebunan swasta maupun perkebunan milik negara seperti PTPN, karena perkebunan besar umumnya memiliki akses jalan yang baik.

5. Pabrik kayu karet belum terdapat di semua lokasi

Nilai kayu karet sangat dipengaruhi oleh jarak dari kebun ke pabrik pengolah, karena semakin jauh, biaya transport semakin besar dan harga yang diterima pekebun semakin rendah. Radius maksimal dari kebun ke lokasi pabrik yang masih layak untuk pemasaran kayu karet adalah 200 $\mathrm{km}$.

6. Pembangunan pabrik kayu karet yang terlalu berdekatan

Adanya pabrik kayu karet yang lokasinya terlalu berdekatan menimbulkan persaingan yang tidak sehat, terutama pada saat suplai kayu karet berkurang. Oleh karena itu, izin pendirian pabrik kayu harus mempertimbangkan keberadaan pabrik yang telah ada. Namun demikian pihak pabrik kayu karet dapat juga berkoordinasi satu dengan yang lain, misalnya pabrik $M D F$ menerima kayu berdiameter $8-14 \mathrm{~cm}$, sedangkan untuk kayu dengan ukuran 
diameter $>15 \mathrm{~cm}$ diterima oleh pabrik veneer atau sawn timber.

\section{Perizinan angkutan kayu karet}

Pengangkutan kayu karet di tingkat supplier harus memiliki SKAU (Surat Keterangan Asal Usul). Berdasarkan informasi dari Dinas Kehutanan, prosedur pengeluaran SKAU adalah dengan mengajukan pembuatan SKAU dari pihak pemohon dengan melengkapi surat keterangan tanah dan keterangan dari Kepala Desa. Setelah dokumen-dokumen dilengkapi oleh pemohon, petugas dari Dinas Kehutanan meninjau lokasi kebun yang akan diremajakan, selanjutnya SKAU diproses dan diterbitkan. Informasi yang tertera pada SKAU meliputi asal kayu (bukti kepemilikan, nomor, nama dan alamat pemilik, tempat muat, dan jenis alat angkut), tujuan pengangkutan (nama dan alamat penerima), serta jenis dan volume kayu. Untuk Kabupaten Muara Enim dan Musi Banyuasin, SKAU ditandatangani oleh Kepala UPTD Kehutanan daerah setempat, sedangkan kabupaten selain dua kabupaten tersebut, SKAU ditandatangani oleh Kepala Desa yang bersangkutan. Setiap lembar SKAU berlaku untuk setiap truk yang mengangkut kayu karet, padahal setiap hektar kebun karet dapat menghasilkan 8 25 truk kayu karet. Hal ini dinilai kurang efisien, sehingga dirasakan perlunya penyederhanaan perizinan untuk pemasaran kayu yang berasal dari tanaman budidaya seperti karet.

\section{Kemitraan Pabrik Kayu Karet dan Petani}

Fluktuasi supply bahan baku selama satu tahun dirasa cukup bagi pihak pabrik, meskipun pihak pabrik harus melakukan beberapa strategi untuk menjamin kecukupan bahan baku selama setahun, di antaranya dengan membangun Hutan Tanaman Industri, menjalin kemitraan dengan petani yang meremajakan kebun karet tuanya, memberi fee untuk supplier, ataupun dengan mencampur kayu yang lama dengan kayu yang baru dengan perbandingan $60 \%$ kayu lama dicampur dengan $40 \%$ kayu baru. Salah satu pabrik memberi fee kepada supplier sebesar Rp $2000 / \mathrm{m}^{3}$ untuk setiap $100 \mathrm{~m}^{3}$ kayu karet yang dibawa ke pabrik.
Beberapa pabrik pengolahan kayu di Sumatera Selatan telah melakukan kemitraan dengan petani dalam pemanfaatan kayu karet, sebagai contoh salah satu pabrik MDF membina dan memberi bantuan modal usaha bagi 2 penangkar bibit karet. Penangkar diberi pinjaman modal sebesar 30 juta rupiah oleh pihak pabrik untuk membuat bibit karet polibeg sebanyak 4000-5000 polibeg. Penangkar harus mengembalikan pinjaman modal tersebut sebesar $40 \%$ dari total pinjaman. Sumber entres dan biji dibantu oleh pihak Dinas Perkebunan Kabupaten terkait. Bibit yang dihasilkan oleh penangkar, ditawarkan kepada petani yang menjual kayunya ke PT Sumatra Prima Fibreboard dengan memperhitungkan nilai kayu karetnya. Program kemitraan ini sudah berjalan sejak tahun 2008 dan sampai dengan tahun 2011 telah tersalur 10.000 bibit untuk petani yang meremajakan kebun karetnya. Di samping itu, petani ditawarkan Garlon (racun tunggul). Pola kemitraan lain dilakukan oleh pabrik veneer yang memberikan bantuan bibit sengon melalui supplier serta ada pula yang memberi bantuan bibit jabon kepada supplier (10 batang bibit jabon untuk setiap $10 \mathrm{~m}^{3}$ kayu karet yang dijual ke pabrik).

Program kemitraan pabrik dan petani merupakan suatu bentuk kelembagaan yang sangat baik untuk dikembangkan. Namun pada kenyataannya masih ditemukan kendala untuk melanjutkan program kemitraan ini, terutama kendala ketersediaan sumberdaya manusia untuk membina penangkar. Dari hasil wawancara, diketahui bahwa dari dua orang penangkar yang dibina, hanya satu orang penangkar yang berhasil menyalurkan bibitnya kepada petani.

\section{KESIMPULAN DAN SARAN}

Provinsi Sumatera Selatan memiliki potensi yang cukup besar untuk pengembangan industri kayu karet, baik dari sisi ketersediaan bahan baku maupun dari sisi industri pengolahan kayu karet. Pemasaran kayu karet di Sumatera Selatan melibatkan pihak supplier sebagai penghubung antara petani dan pabrik. Supplier membeli kayu karet dari petani untuk kemudian dibawa ke pabrik 
pengolahan kayu karet. Beberapa pabrik telah melakukan kemitraan dengan petani dalam pemanfaatan kayu karet misalnya dengan membina dan memberi bantuan modal usaha kepada penangkar bibit, dimana bibit yang dihasilkan, ditawarkan kepada petani yang menjual kayu, dengan memperhitungkan nilai kayu karetnya. Selain itu ada pula yang memberi bantuan bibit sengon dan jabon melalui supplier. Program kemitraan pabrik dan petani merupakan suatu bentuk kelembagaan yang sangat baik untuk dikembangkan terutama dalam rangka pemanfaatan kayu karet hasil peremajaan di tingkat petani.

\section{DAFTAR PUSTAKA}

Antoro, R. 2012. Kayu karet sebagai substitutsi kayu hutan alam. Majalah Kehutanan Indonesia Edisi IV Tahun 2006. www.dephut.go.id di unduh tanggal 1 Maret 2012.

Arsjad, A. dan R. Dereinda. 1988. Potensi dan nilai ekonomi beberapa klon karet dalam menghasilkan bahan baku bagi industri mebel. Lokakarya Pemuliaan Tanaman Karet. Medan, 12-14 Januari 1998.
Boerhendhy, I., C. Nancy, dan A. Gunawan. 2003. Kayu karet dapat menggantikan kayu hutan alam. Warta Penelitian dan Pengembangan Pertanian 25(1), 3-5.

Dinas Perkebunan Provinsi Sumatera Selatan. 2012. www.disbunsumsel. com di unduh tanggal 3 Januari 2012.

Nancy, C., D. S. Agustina, L. F. Syarifa. 2011. Potensi kayu karet hasil peremajaan milik petani vs ketersediaannya untuk memasok industri kayu. Makalah disampaikan pada Workshop Nasional "Perumusan Arah Kebijakan Nasional dan Program Aksi Pemanfaatan Kayu Karet Hasil Peremajaan Milik Petani dan Perusahaan Karet dengan Partisipasi Stakeholder Utama". Jakarta, 21-22 Desember 2011. Tidak dipublikasi.

Manurung, T. 2003. Laju kerusakan hutan Indonesia, terparah di planet bumi. Majalah Gatra, November 2003.

Team Koordinasi Industri Hasil Hutan (TKIHH) Plus. 1987. Usul landasan penentuan kebijaksanaan pengusahaan kayu karet. Jakarta. Tidak dipublikasi. 